
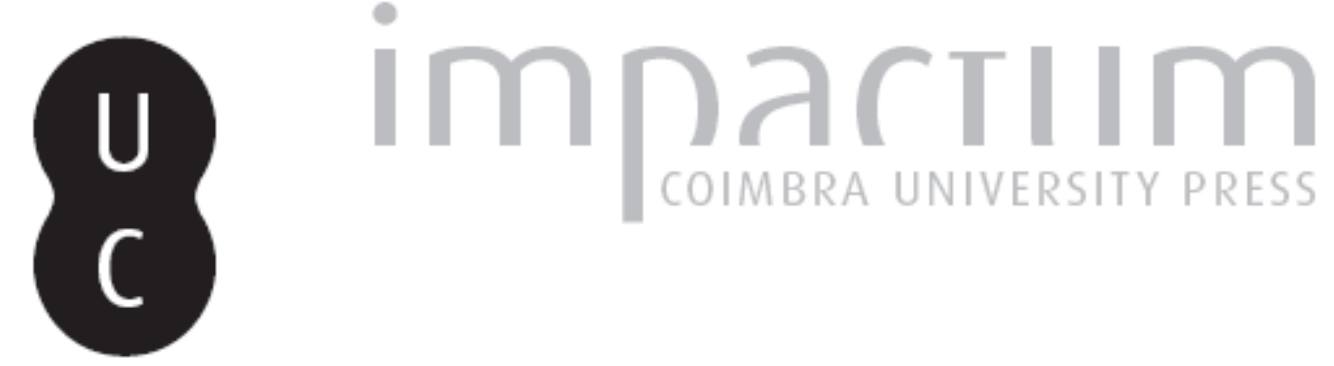

\title{
[Recensão a] Estudos do Século XX: Crises do Século. Coord. Maria Manuela Tavares Ribeiro. N. 10 (2010)
}

Autor(es): $\quad$ Chorão, Luís Bigotte

Publicado por: Imprensa da Universidade de Coimbra

URL

persistente:

URI:http://hdl.handle.net/10316.2/36758

DOI:

DOI:http://dx.doi.org/10.14195/1647-8622_11_31

Accessed : $\quad$ 26-Apr-2023 14:19:41

A navegação consulta e descarregamento dos títulos inseridos nas Bibliotecas Digitais UC Digitalis, UC Pombalina e UC Impactum, pressupõem a aceitação plena e sem reservas dos Termos e Condições de Uso destas Bibliotecas Digitais, disponíveis em https://digitalis.uc.pt/pt-pt/termos.

Conforme exposto nos referidos Termos e Condições de Uso, o descarregamento de títulos de acesso restrito requer uma licença válida de autorização devendo o utilizador aceder ao(s) documento(s) a partir de um endereço de IP da instituição detentora da supramencionada licença.

Ao utilizador é apenas permitido o descarregamento para uso pessoal, pelo que o emprego do(s) título(s) descarregado(s) para outro fim, designadamente comercial, carece de autorização do respetivo autor ou editor da obra.

Na medida em que todas as obras da UC Digitalis se encontram protegidas pelo Código do Direito de Autor e Direitos Conexos e demais legislação aplicável, toda a cópia, parcial ou total, deste documento, nos casos em que é legalmente admitida, deverá conter ou fazer-se acompanhar por este aviso.

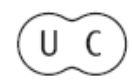


fazer história contemporânea

ESTUDOSDOSÉCULO

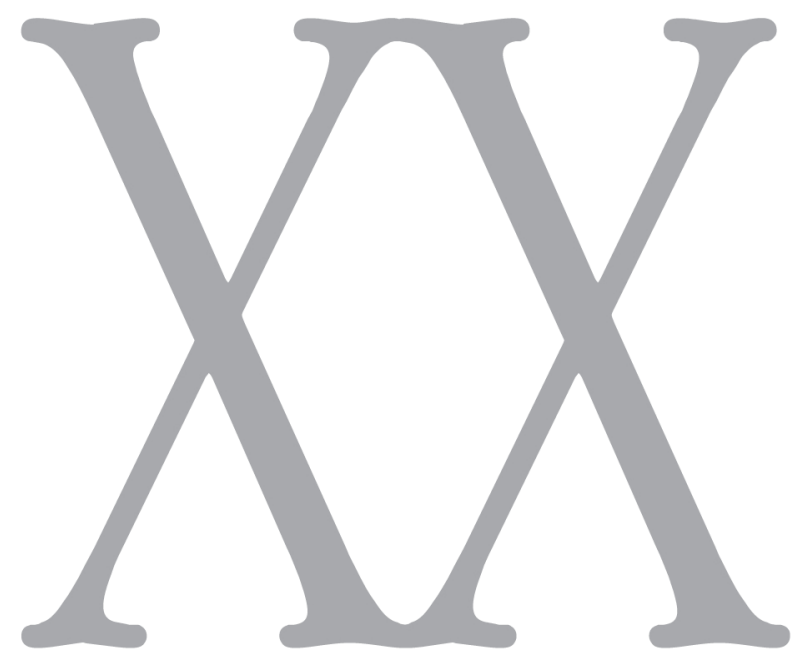

número 11 • 2011

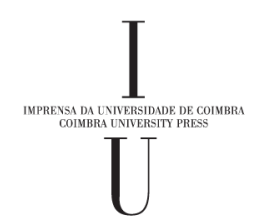


Estudos do Século XX: Crises do Século. Coord. Maria Manuela Tavares Ribeiro. N.o 10 (2010). Coimbra: Imprensa da Universidade de Coimbra. ISSN 1645-3530. ${ }^{1}$

Desejo antes de mais agradecer à Senhora Doutora Maria Manuela Tavares Ribeiro o convite honroso que me dirigiu para participar nesta sessão e felicitá- la na dupla qualidade de coordenadora científica do CEIS20 e directora da Revista pelo lançamento deste número décimo, dedicado às Crises do Século.

Náo seria necessário encarecer nesta circunstância a importância da meditação sobre a Crise, ponto de partida para o tema mais vasto das Crises do Século, mas queria a esse propósito invocar aqui a lição do Senhor Doutor Miguel Baptista Pereira - que nos deixou preciosas reflexóes sobre a Crise e a Crítica -, ao qual se afigurava que da ruína das estruturas tradicionais e do seu suporte metafísico, provocado pela Revolução Francesa, só ficara «uma consciência da historicidade como consciência da Crise», porque em seu entender, «a história em todas as suas dimensóes foi experienciada e julgada como crise».

A perspectiva que ressalta da leitura do vasto conjunto de textos agora reunidos e da sistematização da Revista dão bem nota do seu carácter interdisciplinar, reunindo para a discussão das Crises do Século personalidades de áreas de saber e de origem e formação cultural tão diversificadas, cruzando saberes e experiências, numa amplitude de horizontes verdadeiramente enriquecedora.

\footnotetext{
${ }^{1}$ Este texto foi lido pelo autor na apresentação da revista do CEIS20, realizada em Coimbra, no Teatro Académico de Gil Vicente, em 7 de Dezembro de 2010 .
}

A autonomização no plano da publicação de uma primeira parte dedicada a Crise (s) - Noçôes e Conceitos é em si mesma significativa do reconhecimento da problemática própria que anda associada a esse termo, das dificuldades de conceptualização da Crise.

A visita aos dicionaristas para o esclarecimento do significado e origem etimológica da expressão resulta sobretudo útil na medida em que nos comprova que ao longo do tempo a expressão Crise foi ganhando conteúdo significativo acolhendo o de censura, crítica, juízo sobre o merecimento ou defeitos de alguma obra. Ora, este significado da expressão suscita o que nos parece constituir uma ideia essencial, a de consciência da crise e de crítica a ela associada.

Tal como ensinou Miguel Baptista Pereira, "na consciência da crise, o pólo do "novo" e do futuro rouba a evidência às formas da ordem institucional antiga e torna-as problemáticas; nela gera-se a reflexão ou crítica do passado como diferente e impóe-se ao homem, no presente, o ónus da decisão. A Filosofia Prática é também filosofia da crise, do juízo e da decisão histórica».

Compreende-se assim que logo se tenha procurado esclarecer que Crise traduz um conceito nominativo que se abre a uma pluralidade de conteúdos identificados por critérios diferenciados e correspondentes a perspectivas impossíveis de aproximar», e mais, que a tentativa de lhe conferir «significado científico enfrenta dificuldades que uma riqueza semântica vai seriando». Estas consideraçôes de Adriano Moreira constituem prolegómeno de uma reflexão mais vasta sobre a crise num quadro de "globalização das interdependências", que define o que designa por "crise mundial», que se revela aos olhos do autor, na longa série de crises históricas, pela primeira vez, como crise global e negativa. 
Luís Andrade, por seu lado, discorre sobre várias crises do século $\mathrm{XX}$, sugerindo uma resposta de natureza holística, única que em seu parecer poderá servir a equacionar e resolver as crises actuais do sistema internacional, e Cristina Robalo Cordeiro confronta Bergson e Valéry, para concluir que a "serena duração» do primeiro e o «instante trágico» do segundo conduzem «a duas leituras contrárias da história». Mas à autora não parece exagerado afirmar, muito justamente, que a crise não só faz a história como também a funda, porque «Uma história sem crises quase não é uma história, seja ela governada pela Providência ou abandonada a um mecanismo cego".

Ainda incluído na parte 1., Ángel Rodríguez Gallardo retoma o tema da memória e da desmemória para sobretudo se centrar na análise da crise da «cultura da reconciliação» e na crítica à política de impunidade em relação ao regime franquista, que defende dever ser revista à luz da internacionalização das políticas da memória e do direito internacional.

Por fim, Isabel Baltazar percorre a(s) crise(s) da Europa entre guerras, sustentando que sempre essa crises mostraram o fim de um tempo e o (re)começo de outro, sugerindo em conclusão que a crise é o motor da construção europeia.

A parte 2., dedicada à Crise e Crítica, abre com uma reflexão de Estêvão Rezende Martins sobre «Crise e crítica na história contemporânea». Além de consideraçóes sobre a recepção da Crise no campo historiográfico, e ao carácter multívoco da expressão, Martins define a Crítica como «dimensão substantiva da crise». Apontando o século XX como o século que experimentou "uma espécie de espectro completo das crises da modernidade», considera a Crise como um conceito-chave nas ciências humanas e sociais, já que o seu uso descritivo e interpretativo na historiografia serve para delimitar períodos e estipular transições, qualificar relações entre estruturas e conjunturas, articular duraçóes, apontar quebras de confiança e sensaçóes de insegurança, desempenhando além do mais, Crise e Crítica, em seu critério, um juízo analítico da historiografia contemporânea.

Esse uso interpretativo da Crise revela-se do nosso ponto de vista particularmente relevante no domínio da história política e institucional e das ideias.

Nesse campo, de facto, a Crise constituiu-se não apenas como objecto de estudo, servindo, também, instrumentalmente, como uma espécie de lente de ampliação que permite que se desvende mais nitidamente nas particularidades do seu relacionamento. Com a Política esse relacionamento é tão íntimo, que pode certamente afirmar-se como inimaginável a Política sem referência à Crise e por consequência à Crítica. Por outras palavras, a presença da Crise (e da Crítica) é indispensável à dialéctica que é própria da Política, a qual verdadeiramente lhe confere sentido último.

Compreende-se, assim, que os programas políticos sempre se definam [ou comecem por definir-se] por oposição ou contraponto a situaçóes identificadas como de Crise, sendo que a intencionalidade que os caracteriza, visa, por meio da Crítica, a superação dessas situaçóes.

Nessa medida a Crise pode constituir-se como origem de planos reformadores ou/e revolucionários, no fundamento de rupturas ou na causa de consensos, em justificação de políticas ou/e de alternativa (s).

Ainda na parte 2., Joana Duarte Bernardes ocupa-se do ocaso do eurocentrismo, numa interpelante reflexão sobre a «ideia de Europa» e o discurso intelectual europeu que encarnou no trágico século XX, 
a inevitabilidade do sentimento da crise como marca identitária, revelando a autora a intenção, que foi também a do autor do Discours à la Nation Européene, que revisita, de encontrar uma nova vocação para uma Europa em crise.

Marco Gomes através da análise das repercussóes da suspensão do PDC no XIV Congresso do Partido Comunista Italiano reunido em Roma em Março de 1975 e da questáo aberta com o partido de Berlinguer pela delegação do PCP nesse Congresso, dá notícia de um acontecimento que se insere na história da crise no movimento comunista internacional dos anos setenta, da qual foram realmente protagonistas de primeiro plano, situando-se em campos divergentes, os secretários-gerais do PCI e do PCP.

Isabel Calado retoma o seu tema, o tema da imagem, para a partir de uma incursão pela história da arte contemporânea assinalar a importância da reflexão iconológica enriquecida por novos conceitos, como, entre outros, os da imagem-movimento e imagem-tempo, que permitem aprofundar a ideia segundo a qual a imagem tem conhecido ao longo do tempo formas de ser que nem sempre permitem traçar uma linearidade no seu devir evolutivo, mas antes, revelando rupturas que transformam substancialmente a relação com o mundo das formas visuais, domínio, portanto, em que também se joga a crise, a crítica, como o demonstra a ruptura do neo-realismo cinematográfico através de uma consciência da realidade radicalmente nova.

Mariana Custódio do Nascimento interessa-se pela figura de Edmundo de Bettencourt, recuperando-o do esquecimento como figura do surrealismo, a partir dos seus Poemas Surdos e duma entrevista dada por Bettencourt a João de Brito Câmara em 1944. Para a autora, o nome de Edmundo de Bettencourt e a sua única produção surrealista mostram-se essenciais para "dilatar, reformular e desenvolver o conhecimento e os debates em torno do surrealismo em Portugal», mas igualmente é sublinhada a importância do seu testemunho sobre a perspectiva crítica presencista, projecto ao qual Bettencourt esteve originalmente associado.

Paulo Cunha, por seu lado, trata do processo de europeização da geração do novo cinema português (1962-74), tomando como ponto de partida um texto do sociólogo Adérito Sedas Nunes que apontava entre as causas de modernizaçáo da sociedade portuguesa nos anos 60 a abertura à sociedade internacional. O que Paulo Cunha pretende é verificar se o modelo de «interpretação» de Sedas Nunes pode porventura ser aplicado às transformaçôes estéticas ocorridas no cinema português a partir da década de 60 , como reacção à crise estrutural em que vivia mergulhado desde finais dos anos quarenta. E reconhecendo a existência de testemunhos evidentes do "clima de modernização" que envolveu a geração que promoveu a afirmaçáo e reconhecimento do novo cinema português, Paulo Cunha observa que a experiência europeia dessa geração terá sido a provável causadora do fracasso comercial de todas as obras desses jovens cineastas.

Isabel Nogueira aprecia a imagem cinematográfica de João César Monteiro, Recordaçóes da casa amarela, à luz da dicotomia abstracçáo-empatia, que assenta sobretudo na tese de Wilhem Worringer, de acordo com a qual a abstracção e a empatia constituíam as duas principais directrizes da arte, e havia de contribuir para a afirmação do expressionismo, que, como lembra a autora, reivindicou, contra o conservadorismo e o academismo, a liberdade criativa e expressiva, consagrando 
a deriva abstracta das artes visuais como superação da crise da pintura - acrescentamos nós -, provocada pelo desenvolvimento da fotografia. No expressionismo cinematográfico inclui-se, entre outras, Nosferatu, O Vampiro, de Murnau que terá influenciado João César Monteiro numa simbiose com o imaginário português que constituíram, de acordo com Isabel Nogueira, «uma forma crítica de compreensão do país e do próprio cinema» por aquele cineasta.

A encerrar a Parte 2., Maria Amélia de Souza Reis reflecte sobre as crises de sentido das políticas públicas de educação sexual.

A parte 3., é dedicada à Crise, Decadência e Regeneração

E sugere uma questão: constitui a crise uma fatalidade da decadência ou é a decadência uma fatalidade da crise

Como recorda Vera Coimbra de Matos na sua reflexão sobre a crise dos totalitarismos, a partir da análise do pensamento activo e crítico de Czeslaw Milosz, a ideia de uma Europa em crise ou da decadência do Ocidente constitui uma controvérsia clássica da filosofia da história, e muito justamente sublinha que a partir do século XIX, essa problemática torna-se num tema de acuidade, assumindo a definição genérica de crítica e crise da modernidade.

Yuriy Pochta, dedica atenção ao problema do fundamentalismo relacionando-o com a crise da pós-modernidade, sustentando uma perspectiva muito crítica das consequências do fenómeno da globalização da angústia do mundo globalizado. Talvez possamos dizer, sem trair o pensamento do autor revelador de crises identitárias que justificam os fundamentalismos, cuja força, mesmo que irracional, lhes advém de constituírem fórmulas de preservação dessas identidades em risco.
Georgios Kontogeorgis retoma, a respeito da crise da paz e das raízes da guerra, numa perspectiva regeneracionista, o tema da necessidade de um paradigma cosmoteórico alternativo, centrado a um tempo da diacronia e sincronia da vida social, que esteja na base de um cosmosistema antropocêntrico centrado na liberdade superador da causa fundamental da guerra identificada com o statocentrisme.

Vera Margarida Coimbra de Matos no seu já referido estudo sobre Milosz, anota como característico do pensamento do poeta, o juízo crítico sobre o cientismo, em seu entender produtor de ilusão e de diluição do real num mundo dominado pela adoração cega da ciência e da tecnologia, o que se constituiria na origem do decadentismo totalitário e chama a atenção para a importância no pensamento de Milosz do mito dos confins orientais, do qual retirava o poeta o ideal da coexistência pacífica entre comunidades étnico-culturalmente diferentes, uma ideia de Europa de paz. [Pergunta final: Conseguirá a EU alargar-se ao leste e conseguirá o leste integrar-se superando europeísticamente ressentimentos pretéritos?]

Aníbal Frias, trata de Fernando Pessoa moderno e anti-moderno, reflectindo o que designa por «adesão crítica à modernidade» de Álvaro de Campos e sobre a ideia do quinto império como resposta à decadência, convite à revisitação do balanço crítico pessoano da experiência política da I República. Numa consideração dita pós-revolucionária, de intenção regeneracionista, lê-se da pena de Pessoa: "Ainda bem que isto vai mal, porque isso é a nossa salvação».

Por fim, Álvaro Garrido aborda o tema da gorada institucionalização da "economia nacional corporativa”, do corporativismo, constitucionalizado, aliás, numa a 
final meramente semântica "República Corporativa”, que diz ter tido a sua lógica política interna estritamente ligada ao processo de construção do Estado Novo, mas igualmente resultante de circunstâncias externas conjunturais - a crise financeira aberta em 1929 - e estruturais, a crise do Estado liberal e a crise institucional do sistema capitalista. A designada por Pires Cardoso, 2. ${ }^{\mathrm{a}}$ arrancada corporativa, nos anos cinquenta, só serviria para demonstrar a redução do corporativismo estado-novista, sobretudo, a retórica.

A $4 .^{a}$ e última parte da nossa revista tem por título: Crise ou Renovação do Republicanismo?

Ricardo la Guardia e Guillermo Pérez Sanchez, reflectem criticamente sobre o que designam por falência da nova ordem internacional do pós-guerra, marcada pelo trânsito do enfrentamento EsteOeste à divisão Norte-Sul, com específicas chamadas de atenção, entre outras, para as questôes islâmica e curda, para a situação afegã e iraquiana, para o enfrentamento Israel-árabe, justificando que se refiram aqui as observaçóes de Adriano Moreira, que no texto já mencionado imputa à crise da governança mundial, a substituição da guerra-fria por uma multiplicação de conflitos militares de custos humanos e materiais incalculáveis, envolvendo o que sugestivamente define por «crise brutal» da violação do direito internacional.

Paulo Alliès, empenhado actualmente no chamado projecto da VI República Francesa, apresenta-nos a defesa da construção europeia de acordo com a ideia republicana, recordando que os pais fundadores da Europa introduziram entre os povos europeus a mediação da Razão e não a das paixóes nacionais. E em seu entendimento foi erguido um sistema que repousa na negação da memória. Parece então a Alliès que deve ser imaginada uma nova noção de fronteira para esse espaço pós-nacional, com um governo próprio, que contribua para assegurar a justa repartição de recursos no quadro duma sociedade de pessoas onde náo se separe a política da economia.

Sérgio Campos Matos, que em tão boa hora nos facilitou a releitura de Silva Cordeiro, responsabilizando-se pela escrita de um apelativo estudo introdutório à 2. a edição de $A$ Crise em seus aspectos morais, retoma a reflexão sobre o tema da consciência da crise no Portugal contemporâneo. A tentativa de compreensão desse fenómeno singular, complexíssimo e até mesmo misterioso, a Decadência, a Crise, necessariamente impóem numa perspectiva de auto-conhecimento (de ponderação sobre o significado profundo da identidade nacional) o contacto com o universo do pensamento da crise e da reflexão crítica, desde logo o do nosso século XIX, pleno de sugestóes, fundamental para o entendimento da crise e da decadência, sobretudo a partir da de fim de século, como o demonstra claramente Campos Matos e o sublinha muito justamente Maria Manuela Tavares Ribeiro na Nota de Apresentação da nossa Revista.

Tiago Avó dedica o seu estudo simbolicamente ao ano de 1936, ano do início trágico da guerra civil espanhola para concluir que esse confronto - dizemos nós -, entre duas concepçóes da vida e do mundo, terá funcionado como «catalizador da política interna portuguesa».

Tem sido notada a superfluidade da utilização do termo Crise na linguagem comum e impressiona, de facto, o número de vezes que a vemos referida.

O domínio do debate parlamentar é a este respeito muito expressivo. Uma consulta através do motor de busca dos diários parlamentares no site da Assembleia da República é elucidativa: tanto durante 
a monarquia constitucional, como durante a I República, em ambas as Câmaras das Cortes e do Parlamento, a menção a Crise ultrapassa as 1000 páginas dos respectivos diários atingindo-se com esse número os limites técnicos da pesquisa.

Naturalmente que esse fenómeno de hiper-referência é perturbante, e justificou mesmo que já tivesse sido proposta uma análise da crise do conceito de crise (meta-crise).

Essa proposta de análise da crise do conceito de crise traduz a final uma realidade da maior relevância: a impossibilidade de subsunção a pré-conceitos ou modelos de uma realidade cuja apreensão é fundamentalmente empírica, o que impóe como necessidade no domínio da historiografia, a distinção entre a consciência e o sentimento da Crise à luz da tensão entre o ideal e a realidade, cujo equilíbrio, escreveu Casais Monteiro, o homem anda há longos séculos procurando, revelando-se cada vez mais irrealizável, pelo que concluía melancolicamente o escritor: o ideal e o real recusaram-se a dar ao homem a chave duma vida harmoniosa e a humanidade acaba sempre por sair ludibriada de todas as experiências...

São muito reveladoras as conclusóes do estudo "Crise e crises no discurso de Salazar» de Luís Reis Torgal. A referência nesses textos a crise revela-a instrumental da mensagem política, servindo, portanto, como argumento justificativo ou caucionador de directrizes de política interna e externa. Nessa medida, a sua consideração nos contextos em que foi utilizada por Salazar abre novas perspectivas de análise crítica dos Discursos.

A 4. ${ }^{\mathrm{a}}$ e última parte da nossa Revista é encerrada por Heloisa Paulo, que retoma um tema da sua especialidade, a Oposiçáo à Ditadura Militar e ao Estado Novo, para partilhar connosco resultados recentes das suas pesquisas, dando notícia de crises nas frentes reviralhistas e oposicionistas, trazendo novos elementos para o conhecimento da acção política do general Delgado durante o seu exílio e as polémicas que a envolveram.

Como jurista habituara-me já à "cultura da crise", permanente no domínio do direito e da justiça, e aprendera por experiência própria que com a crise se relacionava intimamente a crítica; em certo sentido o direito revelou-se-me, na sua dimensão doutrinal ou dogmática e também prática, a um tempo, causa e consequência da crise e da crítica.

E termino, finalmente, renovando as minhas felicitaçóes ao CEIS20, melhor, felicitando-me com o CEIS20 na qualidade de seu investigador pelo lançamento desta revista e agradeço a todos, muito sinceramente, a paciência com que tiveram a gentileza de me ouvir.

Luís Bigotte Chorão Investigador do CEIS20 